\title{
O ensino dos métodos de investigação científica numa universidade particular
}

\author{
TEACHING SCIENTIFIC INVESTIGATION METHODS AT A PRIVATE UNIVERSITY
}

\author{
LA ENSEÑANZA DE LOS MÉTODOS DE INVESTIGACIÓN CIENTÍFICA EN \\ UNAUNIVERSIDAD PARTICULAR
}

\section{Maria do Carmo Querido Avelar ${ }^{1}$, Arlete Silva², Marina Borges Teixeira, Ana Llonch Sabatés ${ }^{4}$}

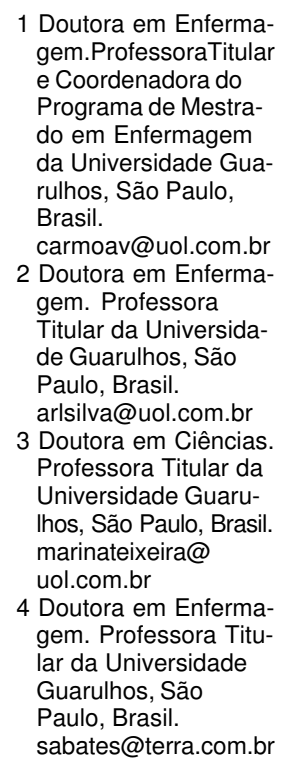

1 Doutora em Enfermagem.ProfessoraTitular e Coordenadora do Programa de Mestrado em Enfermagem da Universidade Guarulhos, São Paulo, Brasil.

carmoav@uol.com.br 2 Doutora em Enfermagem. Professora Titular da Universidade Guarulhos, São Paulo, Brasil. arlsilva@uol.com.br

3 Doutora em Ciências. Professora Titular da Universidade GuaruIhos, São Paulo, Brasil. marinateixeira@ uol.com.br

4 Doutora em Enfermagem. Professora Titular da Universidade Guarulhos, São

Paulo, Brasil.

sabates@terra.com.br

\section{RESUMO}

Este estudo descritivo e exploratório teve como objetivo analisar as facilidades e dificuldades referidas por quinze alunos de cursos de especialização em enfermagem, em relação ao processo de ensino da disciplina Métodos de Investigação Cientifica, focalizado no referencial do paradigma do agir comunicativo. As categorias expressas, como facilidades e dificuldades, em relação ao conteúdo da disciplina, elaboração do projeto de pesquisa e seu desenvolvimento, foram analisadas segundo os tipos padronizados de ação comunicativa. Após a análise, pode-se perceber a emersão de elementos em diferentes níveis de desenvolvimento e interpretados numa seqüência de formas de comunicação, destacando-se por não permitir vislumbrar um compromisso com a inovação ou mudança do processo de ensino, demonstrando as perturbações do consenso neste processo.

\section{DESCRITORES}

Pesquisa em enfermagem. Especialização.

Ensino.

\section{ABSTRACT}

The purpose of this descriptive, exploratory study was to analyze, with focus on the referential of the communicative action paradigm, what were listed as ease and difficulties by fifteen students of specialization courses in Nursing concerning the teaching process of the discipline of Scientific Investigation Methods. The categories expressed as ease and difficulties regarding the discipline's content, the elaboration of the research project and its development were analyzed in accordance with the standardized types of communicative action. After the analysis there could be noticed an emergence of elements at different development levels interpreted in a sequence of communication forms that show no commitment with innovation or change of the teaching process, demonstrating the disturbances of the consensus in this process.

\section{KEY WORDS}

Nursing research.

Specialism.

Teaching.

\section{RESUMEN}

Este estudio descriptivo y exploratorio, tuvo como objetivo analizar las facilidades y dificultades referidas por quince alumnos de cursos de especialización en enfermería, en relación al proceso de enseñanza de la asignatura Métodos de Investigación Científica, enfocado en la referencia del paradigma del actuar comunicativo. Las categorías expresas como facilidades y dificultades en relación al contenido de la asignatura, elaboración del proyecto de investigación y su desarrollo, fueron analizadas según los tipos estandarizados de acción comunicativa. Tras el análisis se puede percibir la emersión de elementos en diferentes niveles de desarrollo e interpretados en una secuencia de formas de comunicación, destacándose por no permitir vislumbrar un compromiso con la innovación o mudanza del proceso de enseñanza, demostrando las perturbaciones del consenso en este proceso.

\section{DESCRIPTORES}

Investigación en enfermeria. Especialización. Enseñanza. 


\section{INTRODUÇÃO}

O método científico nasceu das profundas mudanças na forma do homem ver a si e o mundo, permitindo a institucionalização da ciência no século XVII. O modelo de pesquisa nascido na Europa no século XIX, só foi introduzido na América Latina após a $2^{\text {a }}$. Grande Guerra, sendo que nos anos 50 e 60 foram criados os conselhos nacionais para promover e financiar pesquisas científicas, ciência e tecnologia ${ }^{(1)}$.

A pesquisa em enfermagem iniciou-se com Florence Nightingale, na Europa, no século XIX, expandiu-se em meados do século XX e chegou ao Brasil na década de 70, com a criação do primeiro curso stricto sensu, nível de mestrado, dando maior consistência ao seu corpo de conhecimento com a criação dos cursos de doutorado, no início dos anos oitenta ${ }^{(2)}$.

A enfermagem teve sua efetiva entrada no âmbito da investigação científica, há três décadas, deflagrada com a criação e desenvolvimento dos cursos de mestrado e doutorado $^{(3)}$.

Com o aumento da produção científica, observou-se a divulgação do conhecimento por meio dos periódicos. Em decorrência das exigências acadêmicas de produção científica nos anos 90, foram constituídos grupos de pesquisa e núcleos de estudo, que congregaram elementos de diferentes estágios de formação científica (como de iniciação científica, de especialização, de mestrado e de doutorado) $)^{(1)}$.

Especificamente, os cursos de especialização compreendem aqueles que se incluem na categoria de curso de pós-graduação lato sensu, oferecidos aos portadores de diploma de curso superior e direcionados à área profissional, de mercado, com caráter de educação continuada. Têm carga horária mínima de 360 h, não computando o tempo de estudo individual ou em grupo sem assistência docente e de elaboração de monografia de conclusão de curso.

Nesta categoria, os cursos de especialização são oferecidos por instituições de ensino superior ou por instituições credenciadas para atuarem neste nível educacional.

$O$ processo de ingresso em um curso de especialização tem seus critérios definidos de forma independente em cada instituição, sendo geralmente composto de uma avaliação e de uma entrevista.

A oferta de cursos de pós-graduação lato sensu independe de autorização, reconhecimento e renovação de órgãos ministeriais, porém deve atender às exigências da Resolução CNE/CES no. 1, de 3 de abril de 2001, principalmente quanto ao credenciamento da instituição junto ao $\mathrm{MEC}^{(4)}$.
Nestes cursos não há exigência que o aluno apresente previamente um projeto de estudo, embora haja a obrigatoriedade da apresentação de uma monografia ao final do mesmo, que se caracteriza por um trabalho de investigação científica. Essa exigência é pautada na necessidade de desenvolver habilidade para adquirir e gerar novos conhecimentos, aplicáveis à prática da enfermagem de forma sistematizada e crítica.

A pesquisa tem a finalidade de buscar o conhecimento a partir de métodos e linguagem próprios; é algo que estimula interrogações, pede reflexão crítica, intervenção e criação ${ }^{(5)}$.

A pesquisa encontra-se na raiz da consciência crítica e questionadora do profissional com força vital no despertar do questionamento, da inquietação, do desejo da descoberta, criando e produzindo alternativas ${ }^{(6)}$

O saber do profissional está permeado por conhecimentos adquiridos desde a graduação, passando pela pós-graduação, frente à responsabilidade do seu desempenho. Nesse sentido, os cursos de especialização representam uma oportunidade para o desenvolvimento de estudos que possam incluir os aspectos técnico-científicos e éticopolítico-sociais, na dimensão da sua atuação.

A nossa experiência docente mostra que a utilização do método científico tem sido um processo que exige envolvimento e dedicação do professor e aluno, num esforço para superar as inúmeras dificuldades decorrentes da carência na formação pregressa do aluno. O uso do método científico é percebido pelos alunos como incentivo ao desenvolvimento da pesquisa, divulgação dos trabalhos científicos e descoberta de fatos novos ${ }^{(7)}$.

As dificuldades de alunos e também de enfermeiros em realizar trabalhos científicos, principalmente decorrentes de falhas curriculares, foram destacadas em estudo já realizado anteriormente $^{(8)}$.

Frente à situação apresentada, buscou-se estabelecer um processo de reflexão e de análise, desenvolvendo um estudo, tendo como base referencial a Teoria do Agir Comunicativo ${ }^{(9)}$. Considerando as dificuldades e facilidades expressas pelos alunos em relação ao processo ensino-aprendizagem da disciplina Métodos de Investigação Científica, numa tentativa de desvendar uma realidade concreta, acreditou-se na possibilidade de explicitação das contradições e percepções do referido processo frente à diversidade de formas de entendimento.

Assim, o presente trabalho teve como objetivo analisar as dificuldades e facilidades apresentadas pelos alunos dos cursos de especialização em enfermagem, no desenvolvimento da disciplina Métodos de Investigação Científica, em uma universidade privada. 


\section{BASE REFERENCIAL DO ESTUDO}

Neste estudo utilizou-se aspectos da teoria habermasiana, focalizada no paradigma do agir comunicativo. $\mathrm{O}$ agir comunicativo, como conceito do mundo social, constitui-se num componente da compreensão no qual se baseia o agir orientado para o entendimento.

$\mathrm{Na}$ orientação para o entendimento, busca-se harmonizar planos de ação voltados às metas, sob a condição de um acordo existente ou a se negociar sobre a situação e as conseqüências esperadas frente à capacidade de agir, em vista de objetivos e interesses na execução de planos de ação. O agir comunicativo contrapõe-se ao modelo estratégico da ação voltado às estruturas do agir orientado para o sucesso. $\mathrm{Na}$ orientação para o sucesso, as conseqüências do agir, tem como tentativa o alcance dos objetivos da sua ação, influindo externamente por meio de bens e ameaças. As ações dos sujeitos se relacionam estrategicamente, entrosadas em cálculos de ganhos egocêntricos ${ }^{(9)}$.

$\mathrm{O}$ agir comunicativo harmoniza internamente seus planos de ação e suas respectivas metas, sob a condição de um acordo existente ou a se estabelecer sobre a situação e as conseqüências esperadas, especificando as condições para um acordo alcançado comunicativamente. $\mathrm{O}$ agir comunicativo como processo de entendimento visa um acordo de assentimento racionalmente motivado em relação ao seu conteúdo ${ }^{(9)}$.

A teoria do agir comunicativo possui condições para explicar adequadamente os elementos racionais incorporados em diferentes tipos de ação social que incorpora ações estratégicas voltadas ao sucesso - o agir teleológico e as ações voltadas ao entendimento - o agir constatativo, regulativo e o expressivo ${ }^{(9)}$.

O agir teleológico, voltado ao sucesso, incorpora o saber técnico-estratégico, tendo como forma de argumentação o discurso teórico e o saber transmitido seguindo o modelo da tecnologia e estratégias. O agir constatativo incorpora o saber teórico-empírico, tendo como forma de argumentação o discurso teórico, sendo as teorias o modelo de saber transmitido. Este tipo de ação possibilita que as comunicações possam ser criticadas sob o aspecto da verdade de seus enunciados. O agir regulativo integra o saber prático-moral; sua forma de argumentação é o discurso prático e o modelo de saber transmitido são as representações do direito e da moral. $\mathrm{O}$ agir expressivo incorpora um saber da própria subjetividade, o saber prático-estético. As expressões podem ser trabalhadas argumentativamente através da crítica estética. O saber expressivo deixa-se explicitar na forma de valores, base da interpretação das carências e necessidades subjetivas que podem ser transformadas esteticamente em obras inovadoras ${ }^{(10)}$.
MÉTODO

Numa aproximação com o que se deseja conhecer e entender, partiu-se de dados relativos a uma situação vivenciada e presente no campo de interesse, desenvolvendo-se este estudo, utilizando a teoria do agir comunicativo $^{(9)}$, como apropriada para dar sustentação à reflexão crítica na interpretação aproximada da realidade. Tendo como base o concreto vivido sobre o processo ensinoaprendizagem da disciplina Métodos de Investigação Científica, estabeleceram-se dois momentos. O primeiro momento, descritivo, constituiu-se na explicitação dos componentes do grupo, sua posição social, história e inserção no processo ensino-aprendizagem, incluindo no instrumental de coleta, o espaço, o grupo, definição da população e estratégias $^{(11)}$.

No segundo momento, de interpretação, voltou-se para a análise das categorias temáticas que emergiram dos aspectos interpretativos, representando uma realidade empírica a ser entendida, a partir das concepções teóricas definidas para fundamentar essa análise.

Este estudo foi desenvolvido entre alunos dos Cursos de Especialização em Enfermagem, em uma universidade privada da região metropolitana de São Paulo, criada há 4 décadas, contando hoje com aproximadamente 18500 alunos, distribuídos em 42 cursos de graduação em seus quatro campi; cerca de 550 alunos estão matriculados em cursos de pósgraduação, lato sensu e stricto sensu. O curso de graduação em enfermagem desta universidade vem sendo desenvolvido há 26 anos, e conta hoje, com vários cursos de especialização nesta área como: Enfermagem Pediátrica, Enfermagem em Centro Cirúrgico, Enfermagem Obstétrica, Enfermagem em Emergência, Enfermagem na Saúde do Idoso e Enfermagem Psiquiátrica.

Em 2002 iniciou-se o primeiro Curso de Mestrado Acadêmico aprovado pela CAPES, na área de Odontologia, seguido do Mestrado em Enfermagem e o de Análise Geoambiental, em 2004 e 2005, respectivamente.

No momento da realização deste estudo a população alvo era de 26 alunos, dos Cursos de Especialização em Enfermagem em Centro Cirúrgico (21 alunos) e de Enfermagem Pediátrica (5 alunos)

Estabeleceu-se como critérios de inclusão no estudo, que os participantes tivessem finalizado a Disciplina Métodos de Investigação Científica, estivessem presentes na sala de aula no dia da coleta de dados e concordassem em participar, assinando o Termo de Consentimento Livre e Esclarecido.

Assim, participaram desta pesquisa 15 alunos, sendo 12 do Curso de Especialização em Enfermagem em Centro Cirúrgico e 3 do Curso de Enfermagem Pediátrica. 
Para a obtenção dos dados foi elaborado um questionário contendo três partes distintas: a primeira parte incluiu os dados sócio-demográficos dos alunos, como idade, sexo, estado civil, tempo de formado, tempo de trabalho como enfermeiro e local de trabalho. Na segunda parte, constaram as informações sobre a experiência em pesquisa ainda como aluno de graduação em enfermagem (se cursou alguma disciplina com conteúdo sobre métodos de investigação científica e sua duração, se realizou trabalho de conclusão de curso da graduação e se os conhecimentos sobre esse conteúdo foram utilizados por outras disciplinas do Curso) e como enfermeiro (se realizou algum curso sobre método de investigação científica e sua duração, autoria em produção científica, apresentação de trabalhos em eventos e publicações). A terceira parte constou de questões relativas à sua experiência como aluno do Curso de Especialização em Enfermagem, na instituição em foco, sobre o conteúdo da disciplina, a elaboração e o desenvolvimento do projeto, a ser apresentado como monografia.

O questionário foi submetido ao pré-teste, aplicado a três alunos de outros cursos de especialização, visando identificar a clareza, ordenação lógica e pertinência das questões.

Com a autorização da coordenadora dos Cursos e parecer favorável do Comitê de Ética em Pesquisa da Instituição, conforme preconiza a Portaria 196/96/CNS, os dados foram coletados em agosto de 2004.

A coleta de dados foi realizada em sala de aula, em dia letivo normal, em data e horário previamente estabelecidos. Os alunos foram esclarecidos sobre o objetivo do estudo, o sigilo das informações prestadas e a garantia do anonimato.

O tempo médio para o preenchimento do questionário foi de 20 minutos.

Os dados de natureza quantitativa foram analisados por meio da estatística descritiva e os de natureza qualitativa, após a leitura minuciosa e repetida, foram organizados conforme sua similaridade temática, de acordo com a análise de conteúdo de $\operatorname{Bardin}^{12}$, na seguinte sequiência: fase de organização, visando a sistematização das idéias; a pré- análise, uma primeira impressão da concepção do fenômeno e a análise propriamente dita, definindo-se as categorias temáticas que emergiram dos aspectos interpretativos mais amplos na sua formulação, expressos como facilidades e dificuldades do aluno na disciplina Métodos de Investigação Científica, em relação ao conteúdo, elaboração e desenvolvimento do projeto de pesquisa.

Em seguida, foi feita a análise das categorias, interpretando-as num contexto mais abrangente, aproximando achados e explicações, utilizando como referencial o princípio formal pragmático da teoria do agir comunicativo.

\section{CENÁRIO DO ESTUDO}

Os alunos dos cursos de especialização que participaram do estudo eram todos do sexo feminino, com idade média de 34 anos, sendo a maioria casada. Possuíam oito anos como tempo médio de formados e cerca de cinco anos de tempo médio de vínculo de trabalho nos hospitais privados da região metropolitana de São Paulo.

Neste estudo, a predominância do sexo feminino, reproduz a característica histórica da profissão, exercida quase que exclusivamente por mulheres. $\mathrm{O}$ fato dos alunos terem iniciado o Curso de Especialização tendo em média 34 anos, justifica a maioria ser casada e o tempo médio de formado de oito anos.

A maioria dos alunos procedia de instituições hospitalares particulares, demonstrando o interesse em uma área específica do saber profissional como forma de incrementar seus conhecimentos, com vistas a um maior dinamismo e melhores perspectivas da sua prática na instituição.

Os cursos de especialização enfrentam o desafio de formar especialistas para a rede de serviços de saúde, tendo a responsabilidade de despertar no aluno a necessidade de aprofundamento de conhecimentos científicos, numa relação próxima entre teoria e prática $^{(13)}$. Por outro lado, percebe-se que um contingente significativo desses alunos trabalha em instituições hospitalares que não demonstram interesse em dispor de um plano de carreira e de salários, que possa motivar e estimular os profissionais para a busca de maiores conhecimentos.

Sobre os antecedentes dos alunos no curso de graduação, observou-se que a maioria $(66,6 \%)$ cursou disciplinas sobre métodos de investigação científica. Destes, 8 (53,3\%) referiram que a disciplina teve a duração de um semestre letivo, um respondente referiu 2 semestres e outro 3 semestres de duração; entretanto, em nenhuma delas elaborou-se projetos de pesquisa.

Sobre a utilização dos conhecimentos da disciplina, 4 $(26,7 \%)$ responderam que foram importantes na elaboração de outros estudos e em outras disciplinas do curso; $7(46,6 \%)$ referiram não terem utilizado esses conhecimentos e 4 $(26,7 \%)$ não responderam a questão.

Com isso, alunos que já tiveram o conteúdo teórico sobre métodos de investigação científica, não expressaram a experiência concreta, esperada frente ao aprendizado desse conteúdo. A formação depende mais da inserção social e política do educando numa realidade do que da disposição dos conteúdos curriculares nos cursos. Assim, o saber sistematizado é adquirido num processo contínuo que não deve 
ser interrompido para não comprometer as relações construídas na estruturação desse processo. Tem-se, como crença, que as iniciativas simples, cotidianas e persistentes possam conduzir à experiência educacional dinâmica, ampliada e inovadora ${ }^{(14)}$.

Na vida profissional pregressa, pode-se observar que 14 $(93,3 \%)$ alunos não participaram de quaisquer cursos sobre métodos de investigação científica após a graduação, sendo que $10(66,7 \%)$ deles não possuíam autoria em produção científica. Entretanto, 5 (33,3\%) referiram ter participado na elaboração de sete trabalhos, sendo três relatos de experiência, seguindo as etapas do método científico e quatro pesquisas de campo, que foram apresentados em eventos de enfermagem e publicados em periódicos nacionais da área.

Essa situação parece evidenciar que os enfermeiros participantes deste estudo não conseguiram desenvolver o devido preparo para atuarem com competência utilizando alternativas de resolução e de inovações na sua prática cotidiana.

Entre a formação do enfermeiro na graduação e seu desempenho como profissional, verifica-se um consistente descompasso no envolvimento com a pesquisa ${ }^{(15)}$, o que felizmente começa a mudar, tendo em vista que não só o ensino tem buscado soluções, mas também as instituições de saúde, propiciando novos caminhos de atuação na área de pesquisa científica para a enfermagem ${ }^{(16)}$.

Os dados relativos à terceira parte deste estudo, focalizaram a vivência dos alunos na disciplina Métodos de Investigação Científica dos Cursos de Especialização em Enfermagem, e foram organizados considerando o conteúdo da disciplina, a elaboração do projeto e o desenvolvimento do mesmo, sob a perspectiva das facilidades e dificuldades.

As dificuldades apontadas em relação ao conteúdo da disciplina foram: a falta de conhecimento anterior sobre o assunto; tempo insuficiente para a busca de material bibliográfico; falta de disponibilidade para utilizar recursos de informática e duração da disciplina. Ainda, na fase de elaboração do projeto, foram referidas pelos alunos a condição de ser iniciante e a limitação do próprio conhecimento, a falta de recursos de informática, as dificuldades de acesso às fontes de referências recomendadas e o tempo para definição do tema do estudo.

Quanto ao desenvolvimento do estudo, as dificuldades expressas pelos alunos foram a inabilidade para discorrer sobre o tema, a observância do rigor da correção do vernáculo, a complexidade crescente na seqüência das fases do estudo, a exigüidade do tempo para o desenvolvimento da pesquisa, a necessidade contínua de orientações, a burocracia lenta no fluxo do projeto e a demora no retorno dos instrumentos preenchidos.
As facilidades apontadas pelos alunos em relação ao conteúdo da disciplina Metodologia da Investigação Científica foram: a disposição da disciplina na grade curricular e o seguimento das orientações explicitadas no decorrer das aulas.

$\mathrm{Na}$ fase de elaboração do projeto foram referidas como facilidades: a construção conjunta do projeto entre professor e aluno; o estudo estabelecido a partir da familiaridade com um tema da própria vivência e a elaboração do projeto com seguimento de todas as etapas, conforme a seqüência das orientações.

As facilidades relatadas no desenvolvimento da pesquisa foram: a relação entre orientador e orientado (1/3), a orientação individualizada, a dinâmica estabelecida no desenvolvimento do projeto entre orientador e orientado; o tema de estudo motivador; a disponibilidade do orientador; a concretização das fases do estudo e os seminários de debates dos projetos entre orientadores e orientados.

\section{ANÁLISE E DISCUSSÃO}

Estabelecidas as categorias expressas como facilidades e dificuldades em relação ao conteúdo da disciplina, a elaboração do projeto de pesquisa e o seu desenvolvimento, utilizou-se para interpretação a proposta de Habermas, segundo os tipos padronizados de ação social, incluindo: o agir teleológico; o agir constatativo (objetivo); o agir regulativo (social) e o agir expressivo (subjetivo), explicitada no referencial do estudo ${ }^{(10)}$.

Nele, cada ação captada é interpretada como um tipo de ação que incorpora um saber específico, as formas de argumentação desse saber e o modelo de saber transmitido.

Foram vinculados aos diferentes tipos de ação social os elementos expressos nas categorias já referidas, conforme a análise das tendências incorporadas no material captado sobre o ensino da disciplina Métodos de Investigação Científica.

No agir teleológico-estratégico-instrumental inseriu-se a categoria dificuldades relativas ao conteúdo da discipli$n a$, expressando a falta de conhecimento anterior sobre o assunto; tempo insuficiente para busca de material bibliográfico; falta de disponibilidade para utilizar recursos de informática e duração da disciplina. Neste tipo de ação, os conhecimentos e os argumentos estão relacionados com sua causa, podendo ser avaliadas sob o aspecto da sua eficácia, uma vez que incorporam um saber que pode ser alterado, modificado e melhorado através do conhecimento do saber na forma de tecnologias e estratégias.

A categoria dificuldades relativas ao conteúdo da disciplina inserida no agir teleológico, foi interpretada como ação orientada para o acerto, o sucesso. Nesta categoria, 
temos prioristicamente caracterizada a referência da falta de conhecimento anterior sobre o assunto, constatando-se uma tendência voltada aos aspectos cognitivo-instrumentais que incorporam o saber técnico-estratégico, sendo sua forma de argumentação o discurso teórico, expresso no modelo de saber transmitido como tecnologias e estratégias.

No agir constatativo incluiu-se a categoria dificuldades da fase de elaboração do projeto, expressa como a condição de ser iniciante; a limitação do próprio conhecimento; a falta de recursos de informática; as dificuldades de acesso às fontes de referência e tempo para definição do tema de estudo. Incluiu-se também neste tipo de ação, a categoria dificuldades quanto ao desenvolvimento do estudo, como: a inabilidade para discorrer sobre o tema; o rigor da correção do vernáculo; a complexidade crescente das fases do estudo; a exigüidade do tempo para desenvolvimento da pesquisa; a necessidade contínua de orientação; burocracia e demora no retorno do material.

$\mathrm{O}$ agir constatativo constitui-se de ações que incorporam e apresentam um saber explícito - o saber teórico- empírico, possibilitando que as constatações possam ser verificadas e explicitadas sob o aspecto da verdade de seus enunciados. As controvérsias sobre a veracidade dos conteúdos deste processo tem como forma de argumentação o discurso teórico, o qual nada mais é do que a continuação da atividade comunicativa. Assim, as dificuldades da fase de elaboração do projeto e do seu desenvolvimento estabeleceram uma equivalência em relação à sua tendência de vinculação à ação objetiva.

$\mathrm{Na}$ categoria facilidades em relação ao conteúdo da disciplina as referências corresponderam às ações incluídas no agir regulativo (social) como sendo: a disposição da disciplina na grade curricular e seguimento das orientações explícitas no decorrer das aulas. Incluiu-se também no agir regulativo a categoria facilidades na fase de elaboração do projeto como: a construção conjunta entre professor e aluno; tema do estudo estabelecido a partir da própria vivência e seguimento das etapas das orientações.

O agir regulativo como um tipo de ação social está representado por normas e incorpora o saber prático-moral, que pode ser abordado sob o aspecto da sua correção sempre que surgirem dúvidas sobre a validação de sua pretensão. Sua forma de argumentação é o discurso prático, facultando aos seus participantes ao tomarem parte do mesmo, examinarem a correção de uma ação com relação a uma norma social estabelecida ou discutindo a correção da própria norma. Este tipo de ação integra o saber transmitido na forma de representações do direito e da moral. Este tipo de ação está voltado para o entendimento.
A categoria facilidades em relação ao conteúdo da disciplina como: a disposição da disciplina na grade curricular e a categoria facilidades na fase de elaboração do projeto como: a construção conjunta entre professor e aluno, encontram-se prioristicamente inseridas às ações reguladas por normas, apresentando como característica a tendência de inserção ao agir regulativo.

A categoria facilidades no desenvolvimento do estudo" inseriu-se no agir expressivo, ou seja, subjetivo. Assim, foram expressas como: a relação entre orientadores e orientados; a orientação individualizada; dinâmica estabelecida no desenvolvimento do projeto; tema de estudo motivador; concretização das fases de estudo; seminários de debates sobre projetos, entre orientadores e orientados.

$\mathrm{O}$ agir expressivo incorpora um saber acerca da própria subjetividade, o saber prático-estético. As expressões podem ser eventualmente criticadas como não sendo verdadeiras, mas podem ser trabalhadas argumentativamente através da crítica. $\mathrm{O}$ saber expressivo deixa-se explicitar na forma de valores que estão na base da interpretação dos senti-mentos, das carências e das necessidades subjetivas ${ }^{(10)}$.

$\mathrm{O}$ agir expressivo contrapõe-se às estruturas da falsa práxis, à ideologia da técnica e do sistema, conduzindo a um questionamento com tendências que contribuem, num lento trabalho de elucidação discursiva, para a formação de um novo consenso ${ }^{(17-18)}$. Nesta categoria, os elementos incorporados estão orientados para o entendimento, e suas tendências permitem caracterizar a sua vinculação às ações expressivas, considerando-as significativamente incorporadas.

No entendimento possível permitido através das reflexões realizadas ante as características dos elementos expressos nas categorias, os diferentes tipos de ação social foram apresentados nas formas de comunicação voltada ao consenso ou na forma de entendimento. Conforme suas condições estruturais apresentaram-se em processos de diferentes níveis de desenvolvimento que conseguiram atingir, interpretados numa sequiência de formas de comunicação.

Após análise pode-se perceber que as referências expressas sobre a disciplina Métodos de Investigação Científica, destacam-se por não permitir um compromisso que possa expressar a preocupação com a mudança e inovação do processo de ensino, propostas na perspectiva de construção de novos modelos. As tendências contraditórias no âmbito do entendimento dos processos formais de aprendizagem, situam-se nas estruturas que permeiam os tipos padronizados de ação social expressos nas categorias. 
Com isso tem-se uma maior visibilidade das perturbações do consenso no processo de ensino-aprendizagem da disciplina Métodos de Investigação Científica, manifestadas em contextos comunicativos das categorias em relação às dificuldades. $\mathrm{O}$ aparente consenso em esforços dirigidos para mobilizar e criar propostas político - pedagógicas emerge de ações isoladas sem possibilidade de comprometimento dos envolvidos na dimensão estética expressiva e criativa do processo.

\section{CONSIDERAÇÕES FINAIS}

A realização de um trabalho de pesquisa, empregando métodos de investigação científica é uma exigência a ser cumprida no desenvolvimento dos Cursos de Especialização em Enfermagem. A possibilidade do preparo do futuro especialista, com melhor capacidade para interpretar criticamente a realidade objetiva, articulando a concepção da prática da enfermagem a um corpo científico de conhecimentos, vem possibilitar visualizá-la numa dimensão inovadora do saber $^{(19)}$.

Tanto para enfermeiros docentes como para os assistenciais é freqüente a argumentação da importância da pesquisa e o conhecimento de métodos de investigação científica. Os enfermeiros docentes referem não sentir segurança em seu preparo profissional, em relação à pesquisa; de outro lado tem-se a manifestação dos enfermeiros assistenciais sobre suas dificuldades em realizar pesquisas, por desconhecimento. O foco do ensino centrado na elaboração e execução de um projeto pode, via de regra, trazer embutida a despreocupação de vínculo, de continuidade e engajamento dos pesquisadores em projetos mais amplos ${ }^{(20)}$.

Esses fatos levam-nos a reforçar a necessidade de se estabelecer o ensino de métodos de investigação científica o mais precocemente possível, enfatizando-o nos cursos de graduação, para que o seu ensino na pós-graduação encontre campo fértil no desenvolvimento de maior capacitação dos alunos para a utilização do pensamento científico, crítico e reflexivo. Assim, o estudo dos problemas da própria

\section{REFERÊNCIAS}

1. Carvalho EC. A produção do conhecimento em enfermagem. Rev Lat Am Enferm. 1998; 6(1):119-22.

2. Lopes GT. A trajetória da investigação científica no âmbito da enfermagem. Esc Anna Nery Rev Enferm. 2002;6(1):53-62.

3. Cruz EA, Alves MDS, Fraga MNO, Damaceno MMC. Abordagem ética em pesquisas publicadas por um programa de pósgraduação em enfermagem. Texto Contexto Enferm. 2005;14(1):25-32. realidade, de forma científica, vem a ser o instrumento pelo qual pode-se garantir o aprendizado, a mudança, o encontro com o novo. A utilização de estratégias motivadoras da produção de conhecimento vem a ser o recurso possível para a criação de pontes entre a graduação e a pós-graduação, despertando e estimulando a realização de pesquisas, recomendando sua continuidade ${ }^{(21)}$.

A situação explicitada neste estudo, nos obriga a refletir sobre o estabelecimento de novas estratégias não só para a manutenção e reforço de novas propostas mas, sobretudo, para superar os inúmeros aspectos dificultadores.

Da complexidade e diversidade de situações que emergiram, apreendeu-se elementos da realidade dos alunos que poderão subsidiar o estabelecimento e implementação de políticas pedagógicas e de ensino da disciplina. Mesmo representando uma parcela de toda uma realidade, entendemos sua importância como referência para a construção de novas propostas.

Do resultado deste estudo surge, como possibilidade, a revisão dos fatores dificultadores que representam desafios principalmente para os docentes, que têm como responsabilidade a formação de um profissional especialista, cônscio de seus compromissos técnicos, políticos e éticos, na mobilização contínua de um trabalho mais reflexivo e transformador $^{(22)}$.

Espera-se com este trabalho, compartilhar saberes e experiências, implícitos no cotidiano de cada profissional, configurando um novo compromisso no enfrentamento da realidade profissional.

Essas considerações tornam-se relevantes ante a necessidade de revisão e atualização do ensino da disciplina, com adoção de novas propostas pedagógicas pautadas no respeito à pluralidade de concepções. As transformações ocorrem à medida que se constrói uma competência comunicativa que garanta a emersão de uma consciência crítica e aberta, numa atitude de permanente reflexão como decorrência de uma educação política e cidadã ${ }^{(22)}$.

4. Brasil. Ministério da Educação e Cultura. Resolução n. 1, de 3 de abril de 2001. Estabelece normas para o funcionamento de Cursos de Pós Graduação. Diário Oficial da União, Brasília, 9 abr. 2001. Seção 1, p. 12-3.

5. Castilho V. Educação continuada em enfermagem: a pesquisa como possibilidade de desenvolvimento pessoal. Mundo Saúde. 2000;24(5):357-60.

6. Demo P. Pesquisa: princípio científico e educativo. $2^{\mathrm{a}}$ ed. São Paulo: Cortez; 1991. 
7. Padilha MIES, Carvalho MTC. O aluno de graduação e a pesquisa científica. Rev Esc Enferm USP. 1993;27(2):281-95.

8. Lopes CM. Pesquisar para assistir. Rev Esc Enferm USP. 1992; 26(n. esp.):105-18.

8. Habermas J. Consciência moral e agir comunicativo. Rio de Janeiro: Tempo Brasileiro; 1989.

9. Siebeneichlen FB. Jürgen Habermas: razão comunicativa e emancipação. Rio de Janeiro: Tempo Brasileiro; 1989.

10. Avelar MCQ. A prática do enfermeiro de centro cirúrgico [tese]. São Paulo: Escola de Enfermagem, Universidade de São Paulo; 1994.

11. Bardin L. Análise do conteúdo. $3^{\mathrm{a}}$ ed. Lisboa: Edições 70; 2004.

12. Almeida MCP, Robazzi MLCC, Scochi CGS, Bueno SMV, Cassiani SHB, Saeki T, et al. Perfil de demanda dos alunos de pós- graduação stricto sensu da Escola de Enfermagem de Ribeirão Preto/USP. Rev Lat Am Enferm. 2004;12(2):153-61.

13. Gadothi M, Romão JE. Educação de jovens e adultos: teoria, prática e propostas. $2^{\mathrm{a}}$ ed. São Paulo: Cortez/Instituto Paulo Freire; 2000.

14. Moretto EFS. Enfermagem e o SUS: da realidade à possibilidade [dissertação]. Florianópolis: Universidade Federal de Santa Catarina; 2000.
15. Leão ER. Assessoria de pesquisa científica: produção científica dos enfermeiros de uma instituição privada. Cad Centro Univ São Camilo. 2005;11(2):82-7.

16. Freitag B. A teoria crítica: ontem e hoje. $3^{\mathrm{a}}$ ed. São Paulo: Brasiliense; 1990.

17. Habermas J. Conhecimento e interesse. Rio de Janeiro: Guanabara; 1987.

18. Cassiani SHB, Rodrigues LP. O ensino da metodologia científica em oito escolas de Enfermagem da Região Sudeste. Rev Lat Am Enferm. 1998;6(2):73-81.

19. Silva CV, Adami NP. Mestrado em enfermagem pediátrica: avaliação e busca de caminhos para a sua transformação. Rev Paul Enferm. 2000;19(2):39-44.

20. Nascimento MAL, Figueiredo NMA, Porto FR. Estímulo à pesquisa em enfermagem: criando pontes entre a graduação e a pós-graduação. Rev Enferm UERJ. 2002;10(1):25-8.

21. Loureiro M. Despertando para uma prática reflexiva e transformadora entre professores e alunos de enfermagem [dissertação]. Florianópolis: Universidade Federal de Santa Catarina; 2000 .

22. Avelar MCQ, Silva A. Assistência de enfermagem perioperatória: ensino em cursos de enfermagem. Rev Esc Enferm USP. 2005;39(1):46-52. 